\section{Container Substrate-pH Response to Differing Limestone Type and Particle Size}

\author{
Jinsheng Huang \\ Department of Plant Biology, University of New Hampshire, Durham, \\ NH 03824
}

Paul R. Fisher ${ }^{1}$
Environmental Horticulture Department, University of Florida, Gainesville,
FL 32611

William R. Argo

Blackmore Co., 10800 Blackmore Ave., Belleville, MI 48111

Additional index words. calcium carbonate, calcite, dolomite, fineness factor, hydrated lime, substrate $\mathrm{pH}, \mathrm{pH}$ management, particle size distribution, neutralizing value

\begin{abstract}
The objective of this study was to develop reactivity indices to describe the $\mathrm{pH}$ response for liming materials incorporated into container substrates. Three reactivity indices [particle size efficiency (PSE), fineness factor (FF), and effective calcium carbonate equivalence (ECC)] were developed based on lime particle size distribution and lime neutralizing value (NV) in $\mathrm{CaCO}_{3}$ equivalent. Six lime particle size fractions (2000 to 850, 850 to 250,250 to 150,150 to 75,75 to 45 , and $<45 \mu \mathrm{m}$ ) separated from each of three calcitic limes and seven dolomitic limes were used to calibrate PSE, and were based on the increase in substrate $\mathrm{pH}(\Delta \mathrm{pH})$ incited by the particle size fraction relative to reagent grade $\mathrm{CaCO}_{3}$ when mixed in a sphagnum peat substrate at $5 \mathrm{~g} \mathrm{CaCO}_{3}$ equivalents per liter of peat. PSE for calcitic carbonate limes at day 7 (short-term $\mathbf{p H}$ response) were $0.13,0.40,0.78,0.97,1.00$, and 1.00 for 2000 to 850,850 to 250,250 to 150 , 150 to 75,75 to 45 , and $<45 \mu \mathrm{m}$ particle fractions, respectively. Other PSE values were described for dolomitic carbonate limestones and for long-term pH response, and PSE was modeled with a function over time. FF was calculated for a liming material by summing the percentages by weight in each of the six size fractions multiplied by the appropriate PSE. ECC rating of a limestone was the product of its NV and FF. ECC multiplied by the applied lime incorporation rate could be used to predict substrate-pH response. Estimated PSE values were validated in two experiments that compared expected and observed substrate $\mathrm{pH}$ using 29 unscreened carbonate and hydrated lime sources blended with peat. Validation trials resulted in a close correlation and no bias between expected and observed pH values. Revised PSE values are useful to evaluate the reactivity of different limestone sources for container substrates given the fine particle size, short crop duration, and $\mathrm{pH}$ sensitivity of many container-grown crops.
\end{abstract}

The effectiveness of a lime material for neutralizing acidity of substrates depends on its neutralizing capacity, fineness of grinding, chemical composition, and mineralogy (Barber, 1984). Because the dissolution of limestone occurs as a surface reaction, the particle size distribution of a liming material directly influences the dissolution rate and its effec-

Received for publication 14 Dec. 2006. Accepted for publication 13 Mar. 2007.

Use of trade names in this publication does not imply endorsement of the products named or criticism of similar ones not mentioned.

We thank the American Floral Endowment, Blackmore Co., Center Greenhouses, D.S. Cole Growers, Ellegaard, Greencare Fertilizers, Kube-Pak Corp., Lucas Greenhouses, Pleasant View Gardens, Premier Horticulture, Quality Analytical Laboratories, Sun Gro Horticulture, and the UNH Agricultural Experiment Station.

${ }^{1}$ To whom reprint requests should be addressed; e-mail pfisher@ufl.edu

equivalence" (ECC), calculated as a ratio of neutralizing value compared with $\mathrm{CaCO}_{3}$, quantifies the combined effects of particle size distribution and acid neutralizing value
(NV) of a limestone on $\mathrm{pH}$ response, calculated as:

$$
\mathrm{ECC}=\mathrm{FF} \times \mathrm{NV}
$$

PSE values have been defined for agricultural limestone in field soils. Liming particles coarser than $2000 \mu \mathrm{m}$ (retained on a U.S. 10-mesh screen) had no effect on soil $\mathrm{pH}$ (Meyer and Volk, 1952; Motto and Melsted, 1960; Murphy and Follett, 1978; Tisdale et al., 1993). A lime particle size finer than $250 \mu \mathrm{m}$ (passed through a 60-mesh) had $100 \%$ effectiveness for agronomy crops (Barber, 1984; Tisdale et al., 1993). For lime particle fraction $250-2000 \mu \mathrm{m}$, there is some inconsistency between sources on the relative effectiveness for agronomic lime use. However, it is generally agreed that the PSE of three particle fractions of $>850 \mu \mathrm{m}$ (retained on a 20 -mesh screen), 850 to $250 \mu \mathrm{m}$ (passing a 20 -mesh but retained on 60 -mesh screen), and $<250 \mu \mathrm{m}$ (passing a 60 -mesh screen) could be assigned as $\approx 20 \%, 60 \%$, and $100 \%$, respectively, on the basis of a review of published research (Meyer and Volk, 1952; Motto and Melsted, 1960; Murphy and Follett, 1978), lime material review and texts (Barber, 1984; Tisdale et al., 1993), and state extension sources (Little and Watson, 2002; Peters et al., 1996).

PSE could also be used as a reactivity index to characterize lime materials for container substrates, but existing PSE values based on long-term response from coarse lime grades applied in field soils require recalibration. Many limestones used in container substrates are classified as pulverized, superfine (Schollenberger and Salter, 1943), with the majority of particles $<250 \mu \mathrm{m}$. Agronomic PSE values would therefore provide no distinction between these very fine grades of limestone. Furthermore, nursery and greenhouse crop duration (and therefore required lime reaction times) is often only several weeks in length, rather than months or years for field crops and pasture.

In this study, we evaluated the PSE of six particle size fractions ranging from $>850 \mu \mathrm{m}$ (retained on U.S. standard 20mesh screen) to $<45 \mu \mathrm{m}$ (passed through 325-mesh screen) based on a survey of horticultural lime samples. We then quantified FF, NV, and ECC based on the PSE of each limestone. The specific objectives of this project were:

(a) To develop PSE appropriate for horticultural substrates that can quantify the reactivity of fine particles with short-term substrate-pH responses.

(b) To quantify the ECC of a survey of lime sources and validate the relationship between particle size and substrate-pH change.

\section{Materials and Methods}


samples that are used horticulturally in container substrates were used in this study (Table 1). The limestone materials represented a wide range of physical and chemical properties, and came from 14 sources of greenhouse, fertilizer, and substrate companies. The sample included 25 carbonate and four hydrated limes. Moisture content for the tested limestone samples varied from $0.05 \%$ to $1.2 \%$ (data not shown), which is important because increasing moisture decreases effective NV per gram of limestone. Moisture level for our data set was low compared with up to $10 \%$ moisture measured in some agricultural limestones (Barber, 1984).

Based on the $\mathrm{Ca} /(\mathrm{Ca}+\mathrm{Mg})$ ratio, carbonate limestones were categorized into two distinct groups: calcitic limestones and dolomitic limestones (Table 1). The $\mathrm{Ca} /(\mathrm{Ca}+$ $\mathrm{Mg}$ ) ratio for calcitic lime samples ranged from 0.84 to 0.99 , with an average of 0.94 . For dolomitic lime samples, the $\mathrm{Ca} / \mathrm{Ca}+$ $\mathrm{Mg}$ ) ratio ranged from 0.62 to 0.67 , with an average of 0.64 . The overall average $\mathrm{Ca}$ and $\mathrm{Mg}$ content for calcitic lime samples were $34.5 \%$ and $2.2 \%$, respectively, compared with $19.8 \% \mathrm{Ca}$ and $11.3 \% \mathrm{Mg}$ for dolomitic lime samples. Hydrated lime materials included both calcitic and dolomitic sources, with up to $46.7 \% \mathrm{Ca}$ content in calcitic hydrated lime and $19.8 \% \mathrm{Mg}$ in dolomitic hydrated lime (Table 1). In comparison, pure calcite contains $40 \%$ Ca with no magnesium contamination, while pure dolomite contains $21 \% \mathrm{Ca}$ and $13 \% \mathrm{Mg}$.

Tested lime samples contained other nutrient elements and $\mathrm{Al}$, which affects both fertilizer value and lime reactivity. Increasing metal oxide content directly decreases acid neutralizing value, and metal oxide coatings of limestone particles can inhibit limestone dissolution reaction (Warfvinge and Sverdrup, 1989). Fe content varied from $0.03 \%$ to $0.4 \%$, with an average of $0.11 \%$. Mn content varied from $0.004 \%$ to $0.04 \%$, with an average of $0.012 \%$. The average contents of $\mathrm{B}, \mathrm{Al}, \mathrm{P}$, and $\mathrm{K}$ were $0.008 \%$, $0.04 \%, 0.05 \%$, and $1.03 \%$, respectively. Micronutrients $\mathrm{Cu}, \mathrm{Zn}$, and Mo were not at detectable levels. Previous research showed that, at a normal application rate (10 t per ha), many agricultural limestones contain important amounts of $\mathrm{Fe}$ and $\mathrm{Mn}$ for field crops (Chichilo and Whittaker, 1958, 1961). At the recommended incorporation rate of $6 \mathrm{~g} \cdot \mathrm{L}^{-1}$ of soilless container substrates (Nelson, 2003), the tested carbonate lime samples would supply $1.05-2.37 \mathrm{~g} \mathrm{Ca}, 0.02-0.76 \mathrm{~g} \mathrm{Mg}, 1.8-24.2 \mathrm{mg}$ $\mathrm{Fe}$, and $0.24-2.46 \mathrm{mg} \mathrm{Mn}$ in $1 \mathrm{~L}$ of substrate.

The NV of calcitic limes ranged from $94 \%$ to $101 \%$ (Table 1), with an average of $99 \%$. In contrast, the NV of dolomitic limestones varied from $95 \%$ to $108.7 \%$, with an average of $103.4 \%$. Dolomitic lime samples tended to have higher neutralizing capacities than calcitic sample because of the lower molecular weight of $\mathrm{MgCO}_{3}$ compared with $\mathrm{CaCO}_{3}$, although inert impurities decreased $\mathrm{NV}$ in several dolomitic limestones (D1, D3, D4, D8, and D15). The hydrated liming materials, with lower molecular weights than calcium carbonate, had the highest average NV (137.8\%), ranging from 117\% to $163 \%$. The dolomitic hydrates (H1 and H3) had higher NV than calcitic hydrates (H2 and $\mathrm{H} 4)$.

Dry sieving was performed in a sieve shaker for the first $30 \mathrm{~min}$, and each individual sieve was then manually shaken to ensure all fine particles passed through the sieve. The sample was passed through a series of six standard sieves and the results are expressed as percentage passing through or remaining on each sieve: $>850 \mu \mathrm{m}$ (retained on a U.S. standard 20-mesh sieve), 850 to $250 \mu \mathrm{m}$ (retained on a 60-mesh sieve), 250 to $150 \mu \mathrm{m}$ (retained on a 100-mesh sieve), 150 to $75 \mu \mathrm{m}$ (retained a 200-mesh sieve), 75 to $45 \mu \mathrm{m}$ (retained on a 325 -mesh sieve), and $<45 \mu \mathrm{m}$ (passed through a 325-mesh sieve). Each fraction was dried and weighed to obtain its percentage in the sample (Table 1).

Trial 1. The $\mathrm{pH}$ response from the six particle size fractions for the calibration samples and from all unscreened 29 lime samples and reagent $\mathrm{CaCO}_{3}$, was quantified by incorporating the lime samples at $5 \mathrm{~g} \mathrm{CCE}$ per liter of peat substrate. The substrate was a Canadian sphagnum peat (Professional Black Bale Peat, SunGro Horticulture, Bellevue, WA) with long fibers and little dust (Von Post scale 2-3; Puustjarvi and Robertson, 1975). The initial $\mathrm{pH}$ of the raw peat was 3.5. Substrate moisture was brought to container capacity (near saturation point at 500 $\mathrm{mL}$ water per liter of substrate) in a partially open plastic bag and was incubated at room temperature $\left(2{ }^{\circ} \mathrm{C}\right)$ for 11 weeks. Substrate $\mathrm{pH}$ was measured at days $0,1,7,14,21,28$, $35,42,49$, and 77 with three replicates using an Orion $620 \mathrm{pH}$ meter (Thermo Electron Co., Waltham, MA). On each pH measurement date, the solution was squeezed from the substrate into a corner of the bag, without removing the solution or substrate from the bag. Substrate $\mathrm{pH}$ was then measured directly in the solution, and the solution was then mixed back in with the substrate (minimal evaporation occurred).

Trial 2. The 29 unscreened limestone samples and reagent $\mathrm{CaCO}_{3}$ were incorporated into a different peat sample (unlimed $\mathrm{pH}$ 3.7) but from the same commercial source as in Trial 1, at a rate of $5 \mathrm{~g}$ per liter of peat (equivalent to $5 \mathrm{~kg} \cdot \mathrm{m}^{-3}$ or $8.3 \mathrm{lb} /$ cubic yard, not corrected for equal NV). Sample preparation and data collection were consistent with Trial 1 , and substrate $\mathrm{pH}$ was measured on days $0,1,7,14,21,28,35$, and 44 with three replicates.

Quantifying lime reactivity parameters. Three calcitic and seven dolomitic limestone samples were randomly selected from among all 29 commercial limestone samples for the calibration of PSE values (Table 1), including three calcitic and seven dolomitic limestones (Table 1). Because not all limestone samples contained particles $>850 \mu \mathrm{m}$, only five samples were analyzed (C2, D5, D7, D9, and D12) for this particle fraction (Fig. 1A and B). The six particle fractions separated from each of the ten limestone samples were mixed at $5 \mathrm{~g} \mathrm{CaCO}_{3}$ equivalents (CCE) per liter of peat substrate as described below for Trial 1 . Substrate $\mathrm{pH}$ was measured over time, and the $\mathrm{PSE}_{t}$ on day $t$ of a particle size fraction was determined as:

$$
\begin{aligned}
\mathrm{PSE}_{t}= & (\mathrm{pH} \text { increase on day } t) / \\
& (\text { corresponding } \mathrm{pH} \text { increase on } \\
& \text { day } \left.t \text { for reagent } \mathrm{CaCO}_{3}\right)
\end{aligned}
$$

ANOVA was used to evaluate substrate $\mathrm{pH}$ for Trial 1 separately for each measurement date and particle fraction, with chemical type (calcitic or dolomitic) as the main effect, and limestone source as a nested effect within chemical type. PSE values were then calculated based on the screened calibration samples in Trial 1 using Eq. [3]. PSE data for each lime source were analyzed separately by date using PROC GLM of SAS (SAS Institute, 1999) to test effects of lime chemistry (calcitic or dolomitic), particle size fraction, and their interaction. Means for each lime chemistry and particle size fraction were separated by Tukey's HSD $(P \leq 0.05)$. PSE values based on $\mathrm{pH}$ response at day 7 were used to calculate the FF and ECC for all 29 unscreened limestone samples. The relationship between the ECC and pH from Trials 1 and 2 for the unscreened limestones was analyzed using SAS PROC REG, separately by measurement date and trial.

PSE data were also plotted over time for each chemistry and particle size fraction, and a monomolecular curve was fitted for each particle size fraction. The equation of the monomolecular function was

$$
P S E=A\left(1-e^{-k t}\right)
$$

where $A$ represents the maximum effectiveness between 0 and $1, k$ is a rate parameter, and $t$ represents the days after incorporating the lime into peat. The monomolecular function is a symmetrical function that is derivable, separates the magnitude of $\mathrm{pH}$ response $(A)$ from the reaction rate $(k)$, and may therefore be useful for simulating $\mathrm{pH}$ change over time.

Using PSE to estimate pH response. Substrate $\mathrm{pH}$ response following lime incorporation in a peat substrate depends on the initial substrate $\mathrm{pH}$, the buffering of the substrate to change in $\mathrm{pH}$, and the effective applied lime incorporation rate. Substrate buffering $(\mathrm{pHB})$ can be quantified with units of $\Delta \mathrm{pH}$ per milliequivalent of base per liter of substrate $\left[\Delta \mathrm{pH} /\left(\mathrm{meq} \mathrm{CaCO}_{3} \cdot \mathrm{L}^{-1}\right)\right]$. Titration of peat with $\mathrm{Ca}(\mathrm{OH})_{2}$ shows a nearly linear $\mathrm{pH}$ response with increasing application rate of base up to a $\mathrm{pH}$ near 7.0 (Rippy and Nelson, 2005). Because of this linearity, few data points are needed to quantify $p H B$ for a given substrate. In our study, we used the final $\mathrm{pH}$ (day 77 in Trial 1, and day 44 in Trial 2) following incorporation of $5 \mathrm{~g}$ reagent $\mathrm{CaCO}_{3}$ per liter of peat to quantify $p H B$.

One gram of pure $\mathrm{CaCO}_{3}$ equals 1000 / $50.045=19.98 \mathrm{meq}$ of base. The ECC of a particular lime source at a given number of days $t$ after incorporating lime can be calculated 


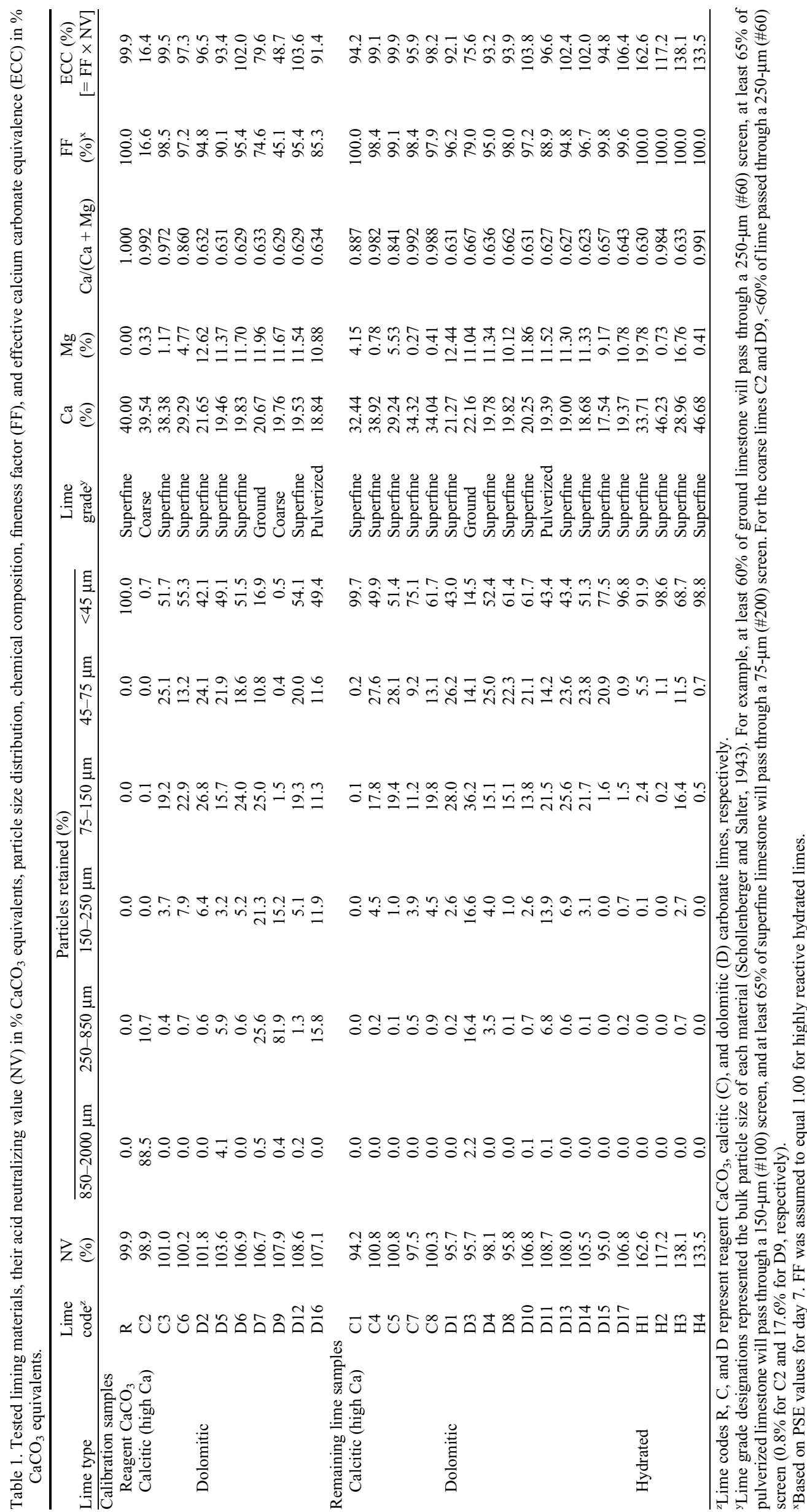



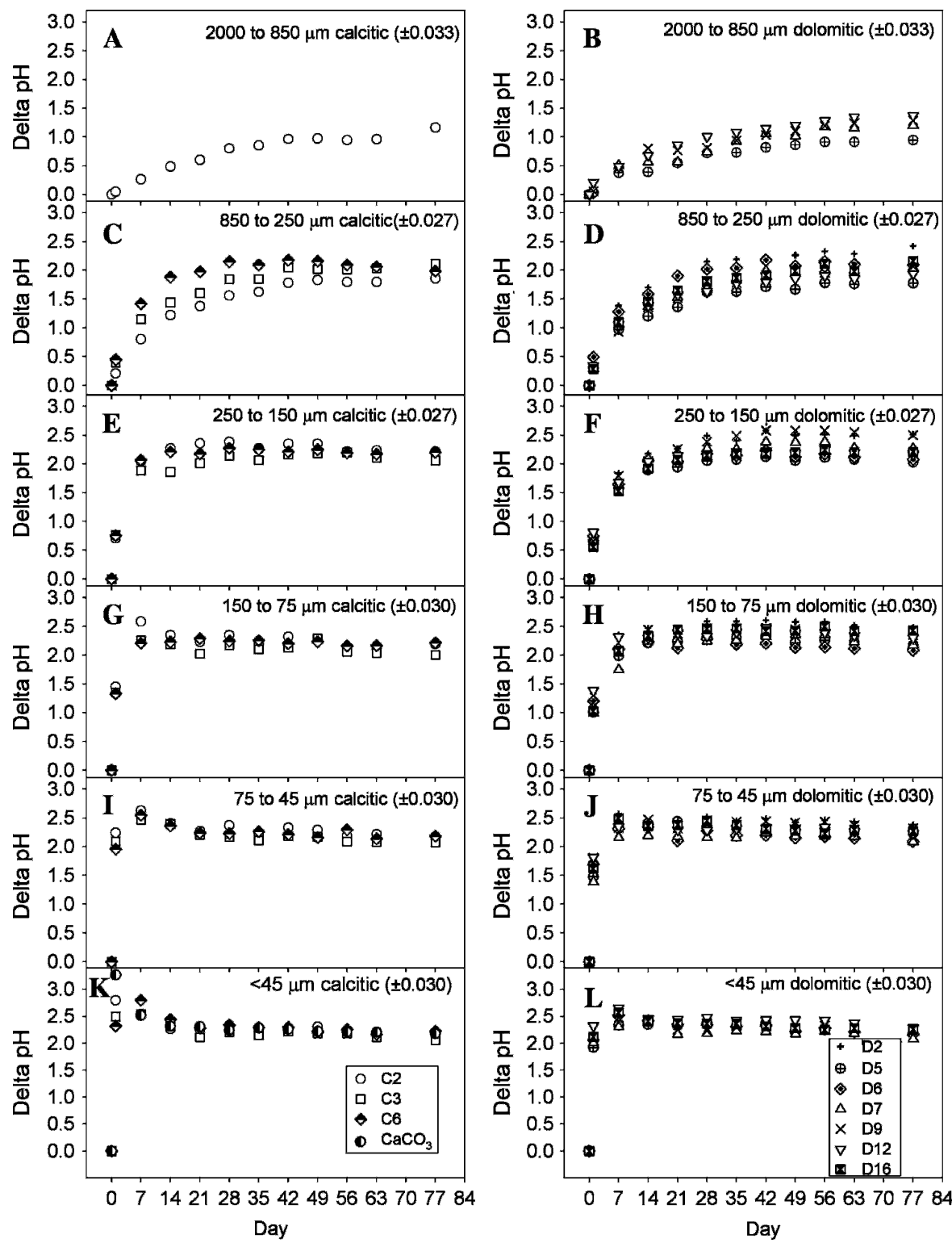

Fig. 1. Changes in the substrate $\mathrm{pH}$ of a peat substrate over time for peat amended with $5 \mathrm{~g} \mathrm{CCE} \cdot \mathrm{L}^{-1}$ for the six particle size fractions of the ten different lime sources in the calibration samples plus reagent grade $\mathrm{CaCO}_{3}$ (calcitic materials- $\mathrm{C} 2, \mathrm{C} 3$, and $\mathrm{C} 6$; dolomitic materials- $\mathrm{D} 2$, D5, D6, D7, D9, D12, and D16). The confidence interval (95\% CI) in parentheses represents the pooled value within the same particle size fraction. Legends for calcitic and dolomitic materials are enclosed in $\mathbf{K}$ and $\mathbf{L}$, respectively. Reagent $\mathrm{CaCO}_{3}$ had only one particle size fraction $(<45 \mu \mathrm{m})$ and was only plotted in $\mathbf{K}$. For the coarsest particle size fraction $(2000$ to $850 \mu \mathrm{m})$ had only one calcitic limestone sample (C2) and four dolomitic limestone samples (D5, D7, D9, and D12). from Eq. [2] using PSE values estimated at time $t$ from Eq. [4], multiplied by 19.98 to give the effective meq of base per gram. The $\mathrm{pH}$ response $\left(\mathrm{pH}_{\mathrm{t}}\right)$ at time $t$ for a given number of grams of applied lime $\cdot \mathrm{L}^{-1}(C)$ can be calculated from

$\mathrm{pH}_{t}=\mathrm{pH}_{\text {init }}+\mathrm{C}\left(\mathrm{ECC}_{t} \times 19.98\right) \times \mathrm{pHB}[5]$

where $\mathrm{pH}_{\text {init }}$ is the initial unlimed substrate pH. We used Eq. [5] to validate our PSE estimates. The substrate $\mathrm{pH}$ for each unscreened limestone was predicted using Eq. [5] for Trial 1 and Trial 2 and was then compared against the observed substrate $\mathrm{pH}$.

\section{Results and Discussion}

Peat $\mathrm{pH}$ responses for different particle size fractions. Reagent $\mathrm{CaCO}_{3}$ had only one particle size fraction, with $100 \%$ passed through a 325 -mesh sieve $(<45 \mu \mathrm{m})$ (Table 1). After $77 \mathrm{~d}$, final substrate $\mathrm{pH}$ from reagent $\mathrm{CaCO}_{3}$ increased by $2.18 \mathrm{pH}$ units (Fig. $1 \mathrm{~K}$ ), which equaled the mean final $\Delta \mathrm{pH}$ for the four finest particle fractions. In contrast, the two coarsest particle fractions had a lower final $\Delta \mathrm{pH}$ (1.18 and 2.03 on day 77 for the $>850 \mu \mathrm{m}$ and 850 to $250 \mu \mathrm{m}$ fractions for both calcite and dolomite, respectively) compared with either finer particles or reagent $\mathrm{CaCO}_{3}$ (Fig. 1). Substrate $\mathrm{pH}$ on day 77 was similar between calcitic and dolomitic chemical types. The mean $\Delta \mathrm{pH}$ on day 77 was 2.14 and 2.19 for calcitic and dolomitic chemical types, respectively (within $0.05 \mathrm{pH}$ unit, $P=$ $0.36)$.

Within a given mesh size, there were differences in $\mathrm{pH}$ response between lime sources, indicating that factors other than particle diameter and $\mathrm{Ca} / \mathrm{Mg}$ balance also contributed to $\mathrm{pH}$ change. For example, variation from the mean $\mathrm{pH}$ on day 77 for a given particle fraction was within $\pm 0.3 \mathrm{pH}$ unit for a particular lime source. On earlier measurement dates, differences from a given lime source and the mean $\mathrm{pH}$ was also within $\pm 0.4 \mathrm{pH}$ unit. Lime reactivity is affected by total surface area including internal pore space (Barber, 1984; Haby and Leonard, 2002; Love and Whittaker, 1954, Parfitt and Ellis, 1966), crystal structure (Rippy, 2005), and iron contamination (Parfitt and Ellis, 1966; Warfvinge and Sverdrup, 1989), which were not evaluated in our study. The moderate level of variation between lime sources at a given particle fraction found in this experiment increases confidence that different lime

Table 2. Particle size efficiency (PSE) estimates based on six screened particle fractions from 10 calibration lime samples on different days after mixing limestone into the substrate in Trial $1 .{ }^{\mathrm{z}}$

\begin{tabular}{|c|c|c|c|c|c|c|c|c|c|c|}
\hline & \multicolumn{2}{|c|}{ Day 1} & \multicolumn{2}{|c|}{ Day 7} & \multicolumn{2}{|c|}{ Day 14} & \multicolumn{2}{|c|}{ Day 28} & \multicolumn{2}{|c|}{ Day 77} \\
\hline Particle size $(\mu \mathrm{m})$ & Calcitic & Dolomitic & Calcitic & Dolomitic & Calcitic & Dolomitic & Calcitic & Dolomitic & Calcitic & Dolomitic \\
\hline $250-850 \mu \mathrm{m}(20-60 \mathrm{mesh})$ & $0.107 \mathrm{~g}$ & $0.106 \mathrm{~g}$ & $0.447 \mathrm{e}$ & $0.442 \mathrm{e}$ & $0.652 \mathrm{~d}$ & $0.620 \mathrm{~d}$ & $0.826 \mathrm{c}$ & $0.803 \mathrm{c}$ & $0.909 \mathrm{~b}$ & $0.933 \mathrm{~b}$ \\
\hline $150-250 \mu \mathrm{m}(60-100 \mathrm{mesh})$ & $0.229 \mathrm{f}$ & $0.213 \mathrm{f}$ & $0.794 \mathrm{c}$ & $0.662 \mathrm{~d}$ & $0.908 \mathrm{bc}$ & $0.866 \mathrm{c}$ & $0.986 \mathrm{ab}$ & $0.976 \mathrm{~b}$ & $0.973 \mathrm{ab}$ & $0.980 \mathrm{a}$ \\
\hline $45-75 \mu \mathrm{m}(200-325 \mathrm{mesh})$ & $0.642 \mathrm{~b}$ & $0.506 \mathrm{c}$ & $0.981 \mathrm{ab}$ & $0.935 \mathrm{ab}$ & $0.993 \mathrm{ab}$ & $0.987 \mathrm{ab}$ & $0.983 \mathrm{ab}$ & $0.993 \mathrm{ab}$ & $0.979 \mathrm{ab}$ & $0.986 \mathrm{a}$ \\
\hline$<45 \mu \mathrm{m}(>325 \mathrm{mesh})$ & $0.778 \mathrm{a}$ & $0.636 \mathrm{~b}$ & $0.987 \mathrm{a}$ & $0.957 \mathrm{ab}$ & $0.986 \mathrm{ab}$ & $0.997 \mathrm{a}$ & $0.990 \mathrm{ab}$ & $0.994 \mathrm{Ab}$ & $0.974 \mathrm{ab}$ & $0.990 \mathrm{a}$ \\
\hline
\end{tabular}

${ }^{2}$ Measured PSE $=(\Delta \mathrm{pH}$ from the lime fraction $) /\left(\Delta \mathrm{pH}\right.$ from reagent-grade $\left.\mathrm{CaCO}_{3}\right)$ for each measurement day. Data were analyzed separately by measurement day, and means were compared with Tukey's HSD at the $P \leq 0.05$ level. 
Table 3. Parameter estimates for the monomolecular function to estimate the particle size effectiveness (PSE) for six lime particle size fractions over time, where $\operatorname{PSE}=A\left(1-e^{-k t}\right){ }^{\mathrm{z}}$

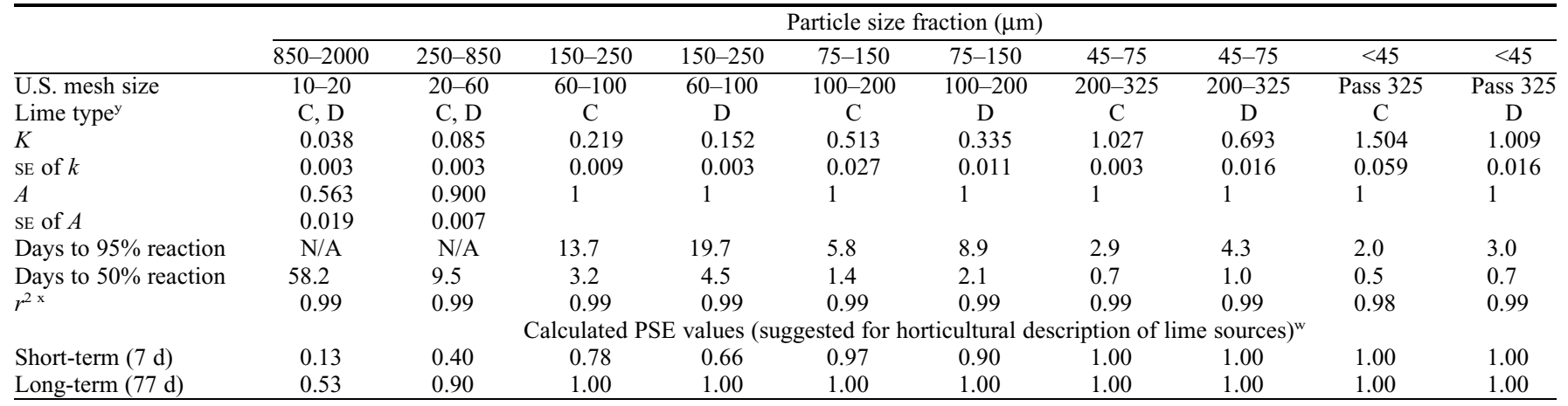

${ }^{\mathrm{z}} A$ represents the maximum effectiveness between 0 and $1, k$ is a rate parameter, and $t$ represents the days after incorporating the lime into peat. Days to $95 \%$ reaction, days to $50 \%$ reaction, and short- and long-term PSE values were calculated using the monomolecular function.

${ }^{\mathrm{y}} \mathrm{C}=$ calcitic, and $\mathrm{D}=$ dolomitic carbonate limes. For the two most coarse particle size fractions, there was no significant difference between PSE for calcitic and dolomitic limes.

${ }^{\mathrm{x}} \mathrm{The} r^{2}$ was determined for a simple linear regression between the estimated PSE using the monomolecular function vs. the measured PSE. Measured PSE $=(\Delta \mathrm{pH}$ from the lime fraction $) /\left(\Delta \mathrm{pH}\right.$ from reagent-grade $\left.\mathrm{CaCO}_{3}\right)$.

"These PSE values are calculated from the monomolecular function in this table based on day 7 ("Short-term") or day 77 ("Long-term"). For highly reactive hydrated lime, PSE can be assumed to equal 1.00 for all particle sizes over both short and long terms.
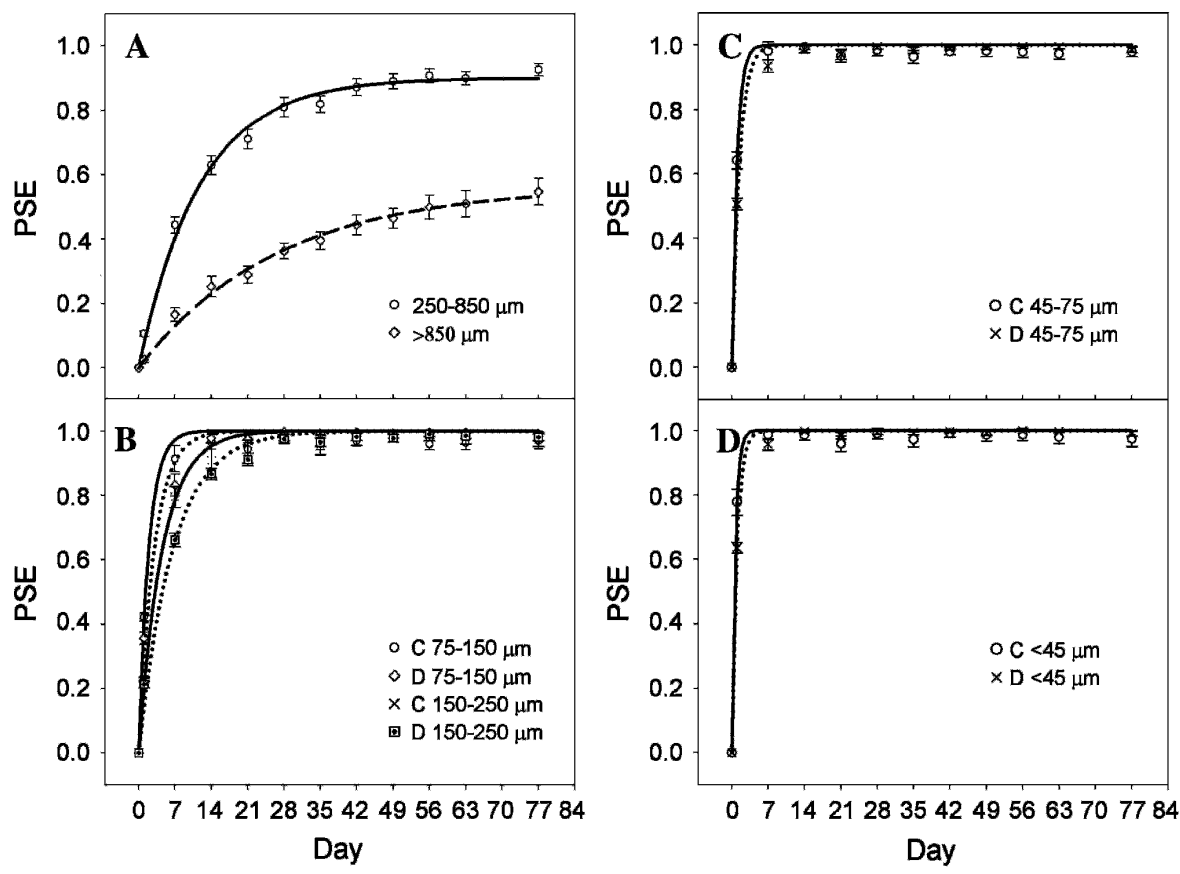

Fig. 2. Reaction curves (shown as lines) estimated with the monomolecular function to estimate the PSE for six lime particle size fractions over time for calcitic (C) and dolomitic (D) carbonate limes, where PSE $=A\left(1-e^{-k t}\right)$ and parameter estimates for $A$ and $k$ are described in Table 3 . Symbols represent the calculated mean PSE with $95 \%$ CIs.

sources had a culturally similar (although statistically different) $\mathrm{pH}$ response at a given particle fraction and that the mean $\mathrm{pH}$ response across lime sources may be a reasonable approximation for estimating PSE. It may also be possible to improve prediction of $\mathrm{pH}$ response by incorporating factors such as total surface area.

The greatest $\Delta \mathrm{pH}$ (3.26) for the reagent $\mathrm{CaCO}_{3}$ occurred $1 \mathrm{~d}$ after incorporation, decreased by day 7 to $\Delta \mathrm{pH} 2.52$, and declined gradually to a final $\Delta \mathrm{pH} 2.18$ (Fig. 1K). The initial rapid $\mathrm{pH}$ increase and subsequent decline were probably incited by an initial disequilibrium with respect to both $\mathrm{CO}_{2}$ and exchange of protons at substrate exchange sites, as discussed by Rippy and Nelson (2005). The finest particle fraction $(<45 \mu \mathrm{m})$ had a similar reaction pattern to $\mathrm{CaCO}_{3}$, with the highest $\Delta \mathrm{pH}$ occurring on day 1 or 7 , with a particularly high initial $\mathrm{pH}$ increase for calcitic lime sources. In contrast, $\Delta \mathrm{pH}$ for the two coarsest lime fractions was still increasing slightly by day 77 . Duration required to increase mean $\Delta \mathrm{pH}$ by at least 2.18 units was $1,7,7$, or $28 \mathrm{~d}$ for the $<45,75$ to 45,150 to 75 , and 250 to $150 \mu \mathrm{m}$ fractions, respectively.

Relative PSE, FF, and ECC. PSE of each particle fraction differed on day 1 such that PSE ranged from 0.013 to 0.778 for calcitic and from 0.028 to 0.636 for dolomitic lime samples (Table 2). By day 77, there were only two statistically separate PSE groups for calcitic limestones $(>850 \mu \mathrm{m}$ and all other particle sizes), and three statistically separate PSE groups for dolomitic limestones ( $>850$ $\mu \mathrm{m}, 250-850 \mu \mathrm{m}$, and all finer particle sizes), with no difference between chemical types. No differences in PSE occurred between chemical types (calcitic vs. dolomitic limes) for the two most coarse particles fractions of $>850 \mu \mathrm{m}$ and $250-850 \mu \mathrm{m}$ on any measurement day, although there were only five limestone sources with $>850 \mu \mathrm{m}$-sized particles, which reduced the statistical power of the analysis to identify differences. For the finer particle fractions, calcitic limestones had a slightly higher PSE than the dolomitic limestones on days 1 and 7. Differences between the two chemical types diminished as time progressed, limestones reacted more completely, and PSE approached 1.

As each particle fraction gradually reacted with the peat acidity, PSE increased over time to a maximum of 1 with a pattern of diminishing returns (Fig. 1). A monomolecular function, Eq. [4], was used to quantify PSE increases over time (Table 3, Fig. 2). Estimates of $A$, the maximum PSE parameter in Eq. [4], were not significantly different from 1 for the four particle fractions finer than $250 \mu \mathrm{m}$, and $A$ was therefore set to a value of 1 in the nonlinear regression for these fractions. In contrast, $A$ equaled 0.563 for the $>850 \mathrm{~mm}$ and 0.900 for the 850 to 250 $\mu \mathrm{m}$ fractions. The largest particle sizes may never completely react in peat, at least during the short time frame for seasonal greenhouse crops. Coarse particles have low exposed exterior surface area in general and may also have greater internal surfaces (or internal pores) than fine particles (Rippy, 2005), both of which would reduce reactivity compared with fine particles. In addition, the surface of limestone particles can become coated by precipitates of $\mathrm{Fe}$ and organic $\mathrm{C}$ from soil 

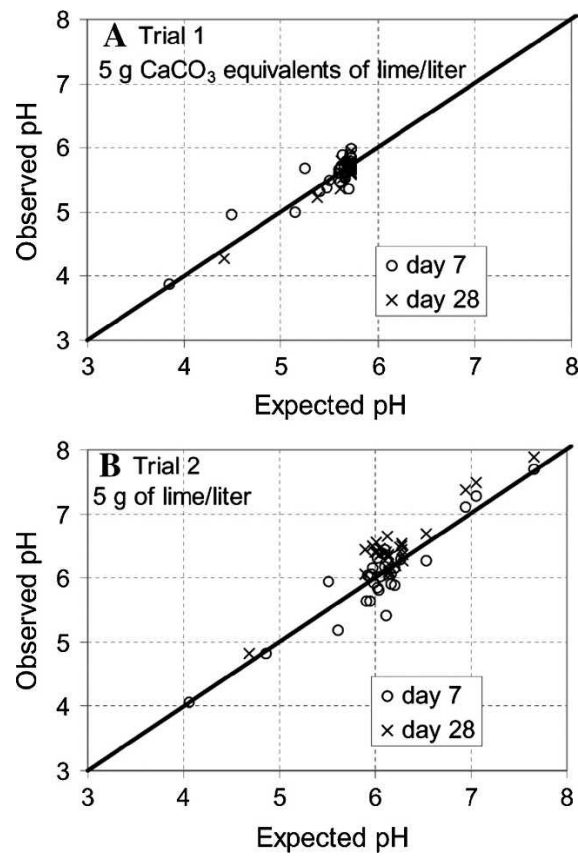

Fig. 3. Comparison between expected and observed substrate $\mathrm{pH}$ at 7 or $28 \mathrm{~d}$ after mixing lime into the substrate, from two trials. Expected pH was calculated using $\mathrm{pH}=\mathrm{pH}_{\text {init }}+\mathrm{C}(\mathrm{ECC} \times 19.98)$ $\times \mathrm{pHB}$, where $\mathrm{pH}_{\text {init }}$ is the initial unlimed substrate $\mathrm{pH}, \mathrm{C}$ is the lime rate $\left(\mathrm{g} \cdot \mathrm{L}^{-1}\right), \mathrm{ECC}$ is the effective calcium carbonate equivalence, and $\mathrm{pHB}$ represents substrate $\mathrm{pH}$ buffering $\left[\Delta \mathrm{pH} /\left(\right.\right.$ meq $\left.\left.\mathrm{CaCO}_{3} \cdot \mathrm{L}^{-1}\right)\right]$. PSE was estimated with the monomolecular function from Table 3 for days 7 and 28. The solid line represents a 1:1 relationship.

solutions (Warfvinge and Sverdrup, 1989). These coatings, formed from the oxidation of amorphous iron carbonate readily precipitating on the mineral surfaces, inhibit limestone dissolution reaction.

The ECC is a measure of expected base strength of a limestone (considering both acid- neutralizing capacity and particle size) and therefore substrate-pH response. For dynamic simulation of $\mathrm{pH}$ over time, the monomolecular function could be used (additional model parameters for substrate buffering capacity, temperature and moisture level would also be part of a substrate-pH model). However, to compare and classify limestone sources, discrete PSE values are needed. All particles smaller than $75 \mu \mathrm{m}$ (passing through a 200-mesh screen) were estimated to react by day 7 , and all particles smaller than 250 $\mu \mathrm{m}$ (passing a 60-mesh screen) were estimated to react by day 77 , as indicated by a PSE of 1.00 in Table 3. Because pH (and PSE) changes over time, the question arises of which measurement day is most appropriate for selecting a PSE value and resulting ECC.
Our suggested PSE values for short- and long-term reaction of limestones in container substrates are shown in the bottom of Table 3 . In Trials 1 and 2, conditions were close to optimum for $\mathrm{pH}$ reaction, with the substrate maintained near saturation and at $22{ }^{\circ} \mathrm{C}$. However, in commercial situations, these reaction conditions can vary widely. For example, the moisture level of compressed bales may start out to be $<25 \%$ while loosefilled bags may be $>40 \%$ saturated. If the bales or bags are exposed to precipitation, then the moisture levels can go much higher. The storage temperature of the substrate can range from $<0$ to $>30{ }^{\circ} \mathrm{C}$. Storage duration can range from $<30 \mathrm{~min}$ to $>4$ months. Once the substrate is placed into a pot, variable moisture levels and temperatures can also occur.

It is our conclusion that a PSE based on day 7 may be most appropriate for short-term crops (4-8 weeks) and as a measure of lime reaction rate, because rapid $\mathrm{pH}$ rise is needed in short-term crops and there is insufficient time for complete lime reaction for coarse particles (Table 3, see "Short-term" PSE values). For long-term crops (2-month duration or more) and as a measure of potential equilibrium-pH, a PSE based on day 77 may be more appropriate (Table 3, see "Long-term" PSE values).

The estimated FF for each lime source was calculated based on the short-term (day 7) and long-term (day 77) PSE values. Shortterm FF (Table 1) for carbonate limes ranged from $16.6 \%$ (coarse: $\mathrm{C} 2$ ) to $100 \%$ (fine: $\mathrm{C} 1$ ) and averaged $89.7 \%$. Long-term FF (data not shown) ranged from $57.3 \%$ to $100 \%$. Multiplying FF by NV, the ECC at day 7 ranged from $16.4(\mathrm{C} 2)$ to $162.6(\mathrm{H} 1)$, indicating that $\mathrm{H} 1$ had 10 times the initial acid neutralizing capacity of $\mathrm{C} 2$.

Validation of $p H$ response. Expected substrate $\mathrm{pH}$ for day 7 and 28 for the unscreened limestones in Trials 1 and 2 was calculated using Eq. [5], where the PSE values were estimated using the monomolecular function for $t=7$ or $28 \mathrm{~d}$ (Table 3). Substrate buffering (pHB, Eq. [5]) was calculated from $\mathrm{pH}$ response with $\mathrm{CaCO}_{3}$ from day 77 (Trial 1) or day 44 (Trial 2) and equaled 0.0225 or $0.0246 \mathrm{pH}$ unit $/ \mathrm{meq} \mathrm{CaCO}_{3}$, respectively. For Trial 1, the lime concentration $(C$ in Eq. [5]) varied between lime sources to equal $5 \mathrm{~g} \mathrm{CaCO}_{3}$ per liter of substrate, whereas $C$ equaled $5 \mathrm{~g}$ for each limestone in Trial 2 (not corrected for NV). Expected and observed substrate $\mathrm{pH}$ are compared in Fig. 3. For all comparisons (day 7 and day 28 in both trials), the intercept did not differ significantly from 0 and the slope did not differ from 1 , indicating that the estimates were not biased. Adjusted $r^{2}$ for the compar- isons ranged from 0.83 to 0.88 , indicating that the majority of variation in substrate $\mathrm{pH}$ was accounted for by Eq. [5] and providing validation of the monomolecular function parameters (see Table 3) for calculating PSE.

\section{Literature Cited}

Barber, S.A. 1984. Liming materials and practices, p. 171-209. In: F. Adams (ed.). Soil acidity and liming. 2nd ed. Agron. Monogr. 12. ASA, CSSA, Madison, WI

Chichilo, P. and C.W. Whittaker. 1958. Trace elements in agricultural limestones of Atlantic Coast regions. Agron. J. 50:131-135.

Chichilo, P. and C.W. Whittaker. 1961. Trace elements in agricultural limestones of the United States. Agron. J. 53:139-144.

Haby, V.A. and A.T. Leonard. 2002. Limestone quality and effectiveness for neutralizing soil acidity. Comm. Soil Sci. Plant. Anal. 33: 2935-2948.

Little, C. and M. Watson. 2002. Understanding value in lime. The Ohio State University Extension Fact Sheet ANR-9-02.

Love, K.S. and C.W. Whittaker. 1954. Surface area and reactivity of limestones. J. Agr. Food Chem. 2:1268-1272

Meyer, T.A. and G.W. Volk. 1952. Effect of particle size of limestone on soil reaction, exchangeable cations, and plant growth. Soil Sci. 73:37-52.

Motto, H. and S.W. Melsted. 1960. The efficiency of various particle size fractions of limestone. Soil Sci. Soc. Amer. Proc. 24:488490.

Murphy, L.S. and H. Follett. 1978. Liming-taking another look at the basics. Agrichem. Age (Omaha) 22:22-26

Nelson, P.V. 2003. Greenhouse operation and management. 6th ed. Prentice-Hall, Englewood Cliffs, NJ.

Parfitt, R.L. and B.G. Ellis. 1966. Studies on Michigan agricultural limestones. Michigan Agr. Expt. Sta. Qrtly. Bul. 49(2):12-23.

Peters, J.B., K.A. Kelling, and E.E. Schulte. 1996. Choosing between liming materials. Univ. of Wisconsin-Extension Publication A3671.

Puustjarvi, V. and R.A. Robertson. 1975. Physical and chemical properties, p. 23-28. In: D.W. Robinson and J.G.D. Lamb (eds.). Peat in horticulture. Academic Press, New York.

Rippy, J. 2005. Factors affecting pH establishment and maintenance in peat moss-based substrates. North Carolina State Univ., Raleigh, PhD Diss.

Rippy, J.F.M. and P.V. Nelson. 2005. Soilless root substrate $\mathrm{pH}$ measurement technique for titration. HortScience 40(1):201-204

SAS Institute, Inc. 1999. SAS/STAT user's guide, version 8. SAS Institute, Inc., Cary, NC.

Schollenberger, C.J. and R.M. Salter. 1943. A chart for evaluating agricultural limestone. J. Amer. Soc. Agron. 35:955-966.

Tisdale, S.L., W.L. Nelson, J.D. Beaton, and J.L. Havlin. 1993. Soil fertility and fertilizers. 5th ed. Macmillan Publishing Co., Inc., New York.

Warfvinge, P. and H. Sverdrup. 1989. Modeling limestone dissolution in soils. Soil Sci. Soc. Amer. J. 53:44-51. 